\title{
VISIBILIZACIÓN DE LA EMIGRACIÓN MAGREBÍ EN EL ESPACIO URBANO
}

\author{
Lic. Dña. Sol Torres Chamorro \\ Universidad Católica de San Antonio. Murcia. España
}

La ciudad no es sólo un espacio fisico sino, y sobre todo, un espacio social. Un lugar claramente delimitado y ocupado por una población organizada de forma más o menos estable, en el que se da respuesta a las necesidades sociales de los individuos y grupos que las constituyen. En ellas se reflejan y manifiestan los distintos grupos, su estructura social, sus normas y valores, sus costumbres y sentimientos, su cultura en definitiva. Son espacios vivos, en continuo movimiento, crisol de grupos diferentes y con intereses divergentes, mosaicos en los que se articulan infinidad de actitudes, identidades, e incluso culturas.

Las ciudades nacen con vocación de ser puntos de encuentro para realizar transacciones de todo tipo. Por lo que su asentamiento se ha ubicado en lugares estratégicos determinados por su función: defensiva, comercial, explotaciones mineras o agrícolas, etc. Lugares que aprovechan las vías de comunicación tradicionales y crean otras nuevas, lo que favorece un amplio flujo migratorio hacia y desde ellos.

Desde la antigüedad las ciudades han sido destino de todo tipo migraciones. El simple desarrollo y crecimiento de las mismas exigia para su construcción y ampliación mano de obra que, por lo general, procedía del campo. Pero también era foco de atracción para artesanos, artistas, viajeros y comerciantes. La ciudad en su desarrollo ha exigido cada vez más servicios, generando nuevos puestos de trabajo, a la par que se ha desarrollado, de forma permanente, un sector y una actividad en un campo que tan sólo era ocasional, el espectáculo. La ciudad próspera aparece como la salvación o una alternativa viable para la gente sumida en sectores degradados. De esta forma periódicamente, coincidiendo con penurias en el sector rural -casi siempre sequías prolongadas-, y al margen de las necesidades de mano de obra o puestos de trabajo que podian ofrecer las ciudades, éstas se han visto invadidas por el éxodo rural.

Las migraciones forman parte de la historia de la humanidad y han sido constantes desde la Prehistoria. Éstas, casi siempre, han obedecido a la misma razón: la de encontrar un mejor asentamiento. No obstante también obedecen a otras causas, como son las económicas, sociales, políticas o intelectuales. Atendiendo al origen de la migración, la más habitual de todas es la migración producida por el éxodo rural hacia los espacios urbanos. La del campesino que espera encontrar en las ciudades lo que la tierra no le ha podido ofrecer. Pero 
en muchos casos esta migración a la ciudad cercana no es más que la primera etapa de un largo éxodo.

En la actualidad, y tras unas décadas caracterizadas por este éxodo rural, las ciudades reciben nuevos flujos migratorios procedentes, principalmente, de otros países. Población extranjera que emigra por distintos motivos, fundamentalmente económicos, pero también políticos, culturales, derivados de los procesos de globalización y movilidad dentro de las empresas transnacionales, etc.

De este modo las ciudades actuales adquieren un tinte mestizo, se convierten un crisol de grupos étnicos en el que los mecanismos de comunicación y de integración operan al lado de las fuerzas competitivas y disgregantes. La ciudad preserva su propia identidad a través de cambios, adaptaciones y variaciones a las que se ve sometida a lo largo de su existencia. En ella aparecen nuevas formas de control social que plantean vínculos de solidaridad entre sujetos y grupos dispersos en el territorio, distantes incluso en el plano social y en el de su experiencia vital. Asimismo, en su urbanismo, aparecen reflejadas las desigualdades económicas y sociales de sus habitantes.

Toda ciudad tiene sus zonas de exclusión en las que se confinan los grupos marginales, los excluidos de la sociedad dominante. Grupos marginales que no son siempre los mismos, sino que se van sucediendo en el tiempo y en el espacio. Y que en el presente se compone, en gran medida, por una población inmigrante extranjera que lo ha hecho por motivos económicos, como es la población magrebí.

Aquí se expondrá cómo la población magrebí ha sido marginada por la sociedad occidental contemporánea, primero en sus propios países durante la colonización y más tarde en las ciudades europeas cuando éstos emigran.

\section{LAS CIUDADES NORTEAFRICANAS}

La expulsión de moriscos y judíos de la península, tras la Reconquista, produjo un flujo migratorio hacia las ciudades del Magreb. A partir de ese momento y hasta el asentamiento masivo de europeos en el periodo colonial, eufemisticamente llamados Protectorados, las ciudades estaban constituidas por tres zonas claramente diferenciadas:

En primer lugar y por orden de antigüedad estaba la Medina, que en la actualidad lo constituye el casco antiguo, fortificado, rodeado de murallas como sistema defensivo, núcleo inicial y que acogía a su población original. En segundo lugar, aparece, con la llegada de los judios expulsados de la península, la mellha o judería contigua a la Medina y extramuros. Y por último, en las afueras de la ciudad aparecen las aglomeraciones de los inaker (plural de tenkira que designa una pequeña cabaña rural cercada) Los tnaker pueden ser de tres tipos: los construidas con adobes, los de cañizo y los nuala o tiendas de piel de animal. La población de los mismos procede del éxodo rural. Estos tnaker son el precedente de los bidonvilles actuales. 


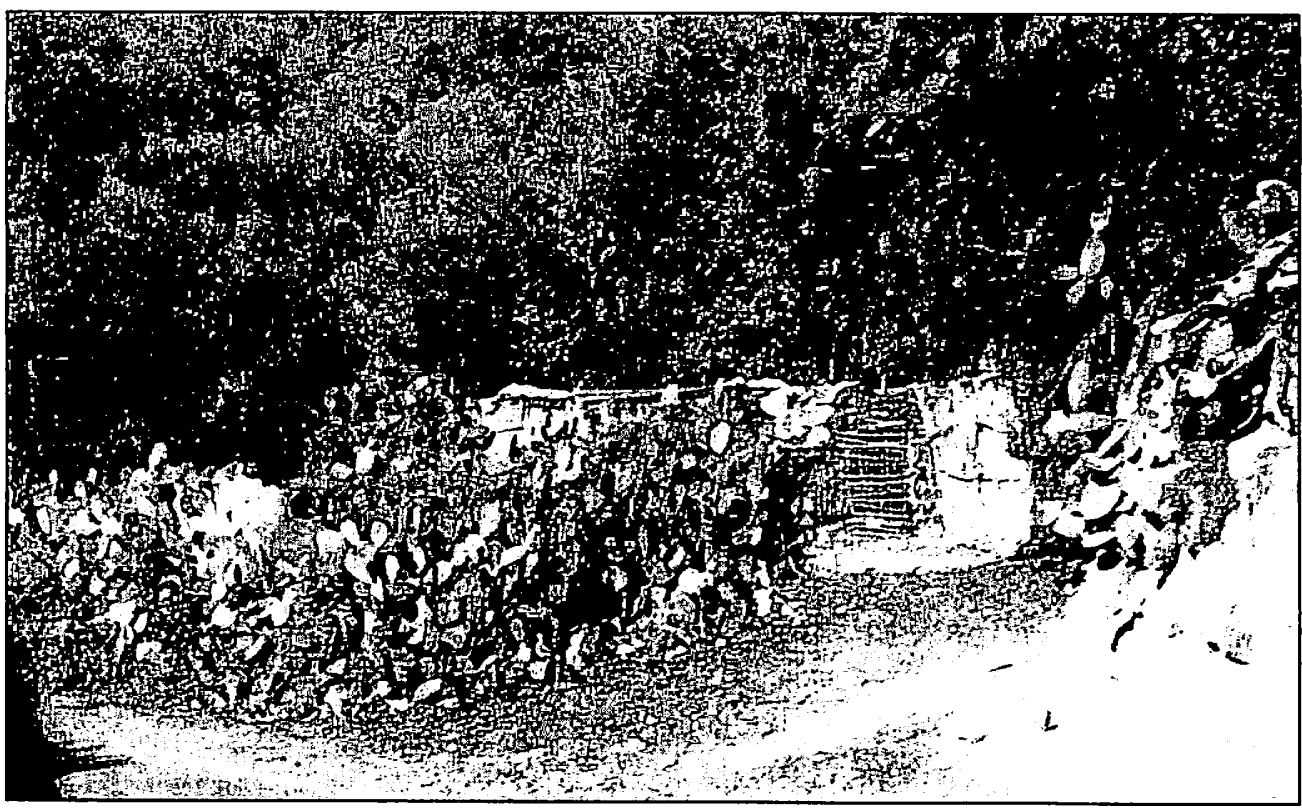

Tnaker en la cordillera del Rif. Se trata de una construcción de adobe cercada, para que no se pueda ver el interior desde fuera. Cerca que pueden ser de madera, caña o bien por medio de una pared de cactus. En este caso la casa posee una doble cerca.

Antes de los grandes planes urbanísticos del periodo colonial ya existía junto a a las zonas tradicionales de la ciudad norteafricana mencionadas (medina, mellha y tnaker) un reservada para los europeos. Con la presencia colonial se produce un desarrollo económico en todo el Magreb. Decenas de millares de colonos se instalarán principalmente en las ciudades, pero también en zonas rurales para desarrollar nuevas formas de explotación agrícola mecanizada e industrial, lo que producirá un nuevo éxodo rural. Se habilitan puertos, se construyen embalses, ferrocarriles y carreteras. Es decir, se inicia la modernización de los paises del Magreb.

Con los objetivos políticos, económicos y militares marcados desde la Metrópolis, el gran artífice de este proceso de planificación colonial fue el mariscal francés Louis-HubertGonzalve Lyautey. De este modo comienza la transformación de las ciudades magrebies, su conversión en beneficio de la población europea.

Las ideas de Lyautey eran claras: preservar la identidad autóctona dando cabida en las ciudades a sus nuevos moradores. Impone una segregación zonal armónica, de forma que coexistan dos ciudades en una, y se permita el desarrollo paralelo de dos sociedades culturales: la europea y la autóctona. Lyautey encargará al urbanista Prost desarrollar su proyecto. Para Prost no se trataba de construir ciudades europeas, sino de ciudades nuevas, fuera y al margen de las ciudades magrebíes y, según sus propias palabras, lo hace "para no invadirlas, deformarlas y desnaturalizarlas"'. Prost, y posteriormente Écochard, aplicaron siste- 
máticamente la segregación zonal que dividia las dos culturas llegando a idear la construcción de autopistas urbanas como sistema de limitación y detención para la expansión de zonas marginales urbanas.

Las expropiaciones en el campo de pequeños propietarios a favor de grandes compañias agrícolas extranjeras y la degradación del mismo producido por años de sequía (1936, 1937,1939 y 1945) aumenta y provoca verdaderas avalanchas migratorias hacia las ciudades que se instalan en barrios marginales (bidonvilles). En ellos pasan a vivir la mayoría de las poblaciones autóctonas.

A partir de la década de los 50 , se producen dos grandes fenómenos migratorios que coinciden con el advenimiento de las independencias de los países del Magreb. La primera, y que precede al regreso masivo de europeos a sus paises de origen, es el éxodo de los judios a su nueva patria, Israel. Esta migración dejará prácticamente vacías las mellha que fueron residencia durante siglos de los judíos. Pronto serán ocupadas por los más afortunados de los que vivían, hasta ahora, en los barrios marginales (bidonvilles). La salida de europeos dejo vacios sus barrios residenciales, que pronto serían habitados, no por residentes de los bidonvilles, sino por la nueva elite gobernante y en el poder que se estrenaba con la Independencia.

La segregación cultural y zonal había desaparecido, pero en su lugar surgió la segregación social.

\section{ESPACIOS DE EXCLUSIÓN EN LAS CIUDADES ESPAÑOLAS}

Desde la década de los 80 el flujo de inmigrantes extranjeros extracomunitarios, procedentes tanto de Africa como de otros países, cobra importancia en España. Este incremento se intensifica considerable a partir del decenio de los 90, a raíz del segundo Proceso de Regularización de 1991. La llegada de estos inmigrantes, su asentamiento en distintas áreas de la geografia española, está transformando paulatinamente la fisonomía de nuestras ciudades.

Si bien el porcentaje de extranjeros no comunitarios en España apenas representa el $1,3 \%$ de la población residente total ${ }^{2}$, lo cierto es que estos no se distribuyen de forma homogénea por todo el país. Las mayores concentraciones de inmigrantes se hallan en la comunidad de Madrid así como a lo largo de la costa mediterránea: Cataluña, Andalucía, Región de Murcia y Comunidad Valenciana. Entre estos inmigrantes el grupo principal lo constituyen los procedentes de Africa, en concreto los magrebíes, quienes representan algo más de las tres cuartas partes de esta migración.

El perfil del magrebí es el de un hombre joven, en torno a los 30 años, soltero o con la familia en el pais de origen. No obstante es cada vez mayor la presencia femenina entre esta población, mujeres que llegan solas o bien por reagrupación familiar.

2 En estos cálculos sólo se toman en cuenta los inmigrantes regularizados, ya que no hay cifras concluyentes sobre los irregulares. No obstante, aunque se tengan en cuenta a los inmigrantes no regularizados el porcentaje no se eleva de forma significativa. 
Esta población magrebí, a pesar de las múltiples campañas de las ONG's para favorecer la no exclusión del colectivo inmigrante, sufre el rechazo de la mayoría de la población. Rechazo provocado por la generalización de estereotipos que sirven para perpetuar una imagen social negativa de los mismos. El hecho de sentirse discriminados refuerza su sentido de la solidaridad, de su pertenencia a un grupo minoritario, por lo que tienden a relacionarse entre ellos, en una actitud en cierta forma defensiva ante la sociedad mayoritaria. El magrebi, sobre todo el recién llegado, tiende a fortalecer los vinculos con su comunidad, como forma de defensa y protección. Esto les lleva a estar física y socialmente aislados, tendiendo a concentrarse en ciertas áreas y barriadas dentro de las ciudades. Espacios en los que pueden mantener, en mayor o menos medida, sus modos de vida diferenciados. Será en el momento en que acceden al mercado de trabajo, al conseguir una ocupación relativamente estable, cuando se desvinculen progresivamente de esta comunidad primera diluyéndose en la sociedad mayoritaria.

No obstante el vivir en áreas degradadas, la infravivienda y en muchas ocasiones el chabolismo, el hacinamiento junto al paro, un nivel bajo de instrucción, etc. constituyen un serio obstáculo para la integración laboral, social y política de esta minoría.

La idea del retorno junto a un proyecto migratorio, en el que se busca el máximo ahorro para poder llevar a cabo sus planes en el país de origen (la construcción de una casa, la compra de un taxi o poner un negocio entre otros), le lleva a reducir sus gastos considerablemente. Habitar en áreas degradas donde los alquileres son bajos, cohabitar en pisos de pequeñas dimensiones con otros compatriotas... favorece ese ahorro de dinero.

La población magrebí, en general, se concentra en barrios degradados de las ciudades y pueblos, bien sea en los cascos históricos o en los barrios de la periferia ${ }^{3}$. Zonas similares a las que residian en sus países de origen al provenir muchos de ellos de los bidonvilles que surgen alrededor de las ciudades más prósperas de Marruecos como Casablanca o Rabat, o de los centros degradados de las ciudades del norte, como Tetuan, Tánger o Nador. De modo que, a pesar de haber emigrado con la idea de mejorar su posición social, se ven obligados a reproducir algunas de las pautas de residencia y comportamiento que deseaban dejar atrás. Pasando a formar parte, de este modo, de las áreas de exclusión de las ciudades.

Los centros urbanos, los aledaños de algunos cascos históricos degradados son una de las áreas de concentración de la población magrebí. Son zonas habitadas por clases modestas, con una población envejecida al haber estado sometida a procesos de pérdida de habitantes que se trasladan a otras zonas de la ciudad, generalmente núcleos residenciales en las afueras. Estas áreas se van deteriorando, los alquileres bajan por las malas condiciones de

3 A propósito de los cascos históricos está la explicación dada por las teorías de Park y de Burguess, representantes de la escuela de Chicago. Ellos consideran que el casco antiguo se reconvierte en un C.B.D. (District Business Center), es decir el lugar de negocio, y a partir de éste se situarán, de forma concéntrica, los espacjos sociales para la habitabilidad, los cuales serán ocupados en virtud de las relaciones de poder existentes entre las clases sociales. Otra teoría es la formulada por Hoyt, llamada teoría sectorial o vectorial. Este autor, frente a los circulos concéntricos de los autores anteriores, establece una tipología vectorial de asentamientos urbanos que serán absorbidos en virtud de las relaciones de poder existentes entre los distintos estratos sociales. 
habitabilidad de las casas, por lo que van entrando en ellas grupos cada vez más pobres. Estos barrios pasan a convertirse en auténticas zonas de exclusión en el corazón de la ciudad.

"Me vine pa'ca, a la Macarena porque aqui están mis amigos. La mezquita. Y porque el alquiler está bien. La casa es vieja, pequeña, la pintamos cuando vinimos. También arreglamos el servicio. Pero la tenemos limpia, se puede vivir. Son dos cuartos y en medio el salón, la cocina es muy pequeña. Vivimos cuatro compañeros alli, pero a veces somos bastantes más." (Rachid, 24 años, originario de Casablanca, residente en Sevilla)

El área central de Madrid (distritos Centro, Chamberí y Tetuán) o el barrio de San Fernando de Alicante son ejemplos de estas zonas degradadas, en las que se concentra la población inmigrante.

En algunas ciudades españolas hay planes de urbanismo que buscan reintegrar estas áreas a la ciudad como ocurre, por ejemplo, en las zonas de la Macarena en Sevilla o Tetuán en Madrid. Estos nuevos planes de urbanismo van desplazando a los habitantes de estas áreas, tanto inmigrantes como antiguos residentes, a otras zonas de la ciudad.

"Nos hemos mudado porque la dueña de la casa va a hacer obras, para ponerla bien dice. Dice que van a durar un año, pero no ha dicho que podamos volver. Nos hemos venido a este barrio [Polígono Norte], mas cerca de los amigos. La casa es pequeña, pero cuesta lo mismo." (Ali, 32 años, originario de Marrakesh, residente en Sevilla)

Otras zonas en las que se concentran los inmigrantes son las barriadas obreras que surgen en las ciudades españolas a partir de los años 50-60, como consecuencia de la política urbanistica de corte paternalista promovida por el Estado. Esta planificación urbana se conoce comúnmente como los "planes de vivienda", destinados a acoger a la población obrera. Un análisis posterior de dicha planificación urbana permite establecer una serie de criticas, entre ellas las malas condiciones de habitabilidad y de higiene, con lo cual el patrimonio residencial que queda hoy en día está bastante deteriorado. Barrios obreros de gran densidad de población, superando en algunas áreas el umbral de hacinamiento y en las que se dan altas tasas de paro, como por ejemplo el distrito Fuencarral en Madrid o el distrito Norte en Sevilla. Estas áreas acogen el crecimiento migratorio de la ciudad, tanto interior: marcha del centro a la periferia, migrantes procedentes de otras regiones del territorio español, etc.; como exterior: migrantes retornados, inmigrantes extranjeros.... Son barrios donde los alquileres son asequibles y en los que una alta densidad de población hace que la presencia de los magrebies pase más desapercibida, a pesar de su tendencia a agruparse por afinidad de origen, minimizando asi el posible rechazo.

En otros casos los inmigrantes pasan a residir en zonas y barrios marginales donde el grupo étnico mayoritario es el gitano. Este es el caso de la zona conocida como "Las tres mil viviendas" en Sevilla o el Parque Ansaldo en las afueras de Alicante. Este último fue construido como un barrio para clases medias que, como consecuencia de una serie de problemas constructivos, fue ocupado progresivamente por gitanos primero y por inmigrantes magrebíes en los últimos años, los cuales alquilan los pisos a los gitanos. Son barrios con 
"mala fama", estigmatizados por la sociedad mayoritaria y evitados por la mayoría de los ciudadanos. Este es un caso representativo de los casos de invasión/sucesión, terminología acuñada por los sociólogos urbanos de la Escuela de Chicago a partir de los años 20 , y que tiene su origen en los Estados Unidos, consecuencia de las oleadas migratorias que llegaron al mismo en esa época.

Son dos los fenómenos que se observan en las ciudades relacionados con la llegada de inmigrantes: El primero se produce cuando el inmigrante pasa a formar parte de las zonas de exclusión de las ciudades, como ya se ha visto, acentuando de este modo su separación de la sociedad mayoritaria, su inclusión en un guetto al reforzar que el barrio siga cerrado sobre si mismo. Y el segundo es la coexistencia de grupos distintos y diferenciados en el mismo barrio: gitanos, magrebíes, sudamericanos, procedentes de países del este... que llegan a configurar una especie de melting pot o crisol de culturas.

A pesar de convivir distintos grupos étnicos en estas zonas marginales o áreas de exclusión, no hay una coexistencia temporal de los mismos, encontrándose incluso separados espacialmente, hasta el punto de que pueden hallarse claramente diferenciadas calles de magrebíes, de paquistaníes o de dominicanos, como ocurre en la Ciudat Vella de Barcelona.

En estos barrios se da lo que los sociólogos de la escuela de Chicago denominan "sucesión". Entendiéndose por sucesión "aquella serie de acontecimientos que sobresalen en la comunidad cuando ésta se desarrolla y crece, transformándose en sus características principales" (Bettin, 1982:78). Un ejemplo clásico de sucesión es el de los grupos étnicos en determinadas áreas, como es el caso que nos ocupa.

En esta sucesión de grupos étnicos se dan varias fases. La primera de ellas es la denominada "invasión", que se produce cuando un grupo comienza a introducirse, de una forma somera pero constante, en el barrio ocupado por otro. Así, la concentración de esta población inmigrante en determinadas áreas urbanas provoca el rechazo social de la mayor parte de los vecinos de la zona, lo que a su vez favorece la marcha de los antiguos residentes de ese barrio.

Ejemplos de esta fase de invasión se encuentran en los primeros momentos de transformación de la Ciudat Vella de Barcelona, así como al comienzo de la ocupación magrebí del Parque Ansaldo de Alicante. Barrios como el de San Juan o la Fama de Murcia están viviendo en la actualidad esta fase: residencia habitual de gitanos, los magrebies van ocupando poco a poco diversos pisos en la zona y abriendo pequeños establecimientos.

"Si antes vivia en el casc antic pero nos fuimos. Primero por el trabajo, para estar más cerca del trabajo. Pero también porque empezaron a llegar moros y sudamericanos, y ya no estabamos a gusto en nuestro barrio." (Carmen, 45 años, Barcelona)

4 Un análisis más profundo de los procesos de invasión/sucesión pasa inevitablemente por el estudio de los procesos de la lógica darwinista que, grosso modo, podria definirse como la "supervivencia del mas fuerte". Y es que, previo a los procesos de invasión/sucesión se dan dos secuencias: cooperación y competencia. Se entiende por cooperación el proceso por el que los individuos se alian en términos de una solidaridad grupal para escoger el lugar más idóneo para establecer su residencia. Junto a esta cooperación existe una competencia entre los distintos grupos al intentar satisfacer sus necesidades de vivienda. 
La segunda fase se denomina de "reacción", de resistencia por parte del grupo que ya estaba en él ante lo que ellos consideran una apropiación del territorio por parte del nuevo grupo. En estos casos son frecuentes los enfrentamientos entre distintos grupos étnicos, como son los enfrentamientos entre gitanos y magrebíes en "Las tres mil viviendas" de Sevilla o los ocurridos entre magrebies y europeos del este en el distrito de Fuencarral de Madrid.

Finalmente llega lo que se podría calificar de "avalancha" de los recién llegados que provoca el abandono rápido de la zona por los antiguos residentes. Como ha ocurrido en el Parque Ansaldo de Alicante o en la Ciudat Vella en Barcelona.

"A veces vuelvo al barrio y no lo reconozco. Esta lleno de marroquies, de dominicanos, hay ruido y música de otros lugares, muchas tiendas de las suyas. Cuando paso por alli tengo nostalgia, pero ya no es igual. No volveria a vivir alli." (Enric, 62 años, Barcelona)

Las zonas de exclusión de las ciudades en las que residen la mayoría de los inmigrantes magrebies son lugares estigmatizados, marginales dentro del espacio urbano. En ellos el paro, el hacinamiento, las escasas condiciones sanitarias ahuyentan a la población mayoritaria de ellos.

No obstante, yendo más allá de lo que se ve a simple vista, se observa que son lugares privilegiados de interacción social (tanto acogedora como conflictiva), lugares en los que las reglas de convivencia son diversas y en los que se confrontan diversos hábitos culturales.

En ellos sus habitantes viven de espaldas unos a otros y, al no haber un campo común de intereses las relaciones interétnicas, son casuales. Los inmigrantes se reúnen en grupos por afinidad de procedencia, estableciendo redes de apoyo y ayuda muy activas, basadas tanto en el parentesco como en la amistad derivada del trayecto migratorio.

Los grupos que conviven en estos barrios, en estas zonas multiétnicas de exclusión, afirman su presencia mediante la estancia en la calle, encontrándose en determinados lugares como bares, plazas o estaciones por donde circula tanto información como transacciones comerciales paralelas a los canales oficiales, abriendo sus propios locales, pequeños comercios como carnicerías halal en las que se vende carne sacrificada según el precepto islámico, etc. Al disponer de locales donde cubrir sus necesidades básicas, el inmigrante deja de ir a otros barrios a buscar lo que necesita, a excepción de los desplazamiento por el trabajo o para visitar a los amigos. De este modo restringen sus relaciones e interacciones a los límites de sus barrios. 


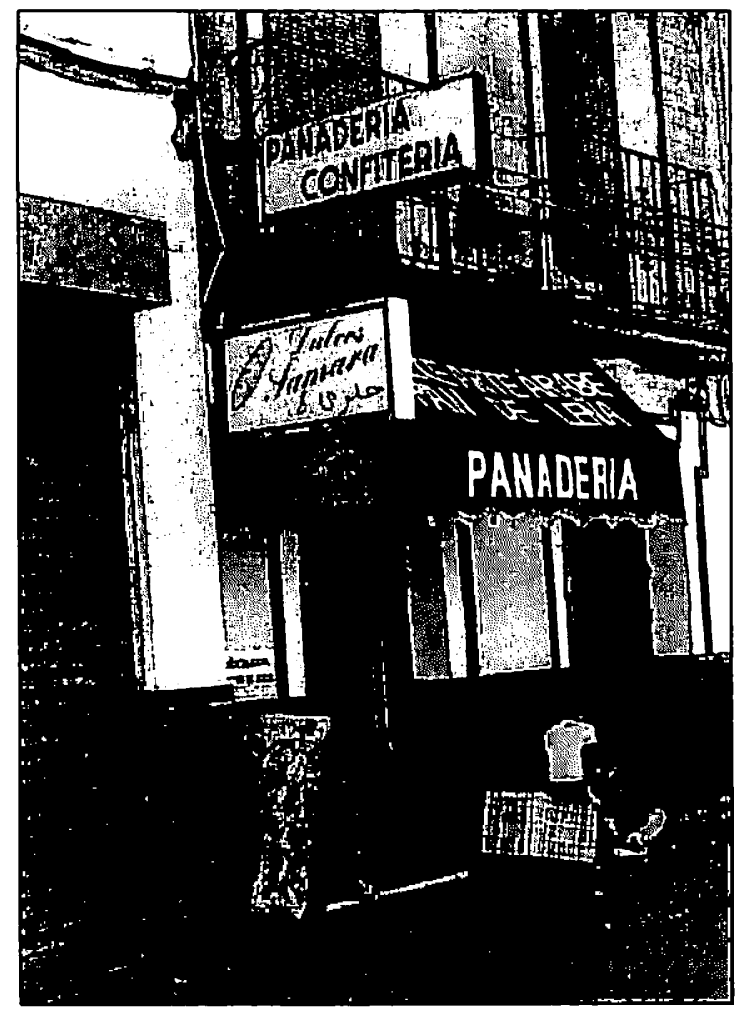

Panaderia regentadas por inmigrantes magre bies en una barriada obrera de la ciudad de Sevilla.

Al mismo tiempo, los magrebies residentes en estas zonas son excluidos sociales en tanto que la sociedad dominante los sitúa estructuralmente fuera de ella. Ellos aceptan y se automarginan también como defensa y protección de un medio que perciben como hostil. En sus barrios consiguen lo necesario para la autoayuda fundamental, y en ellos van desarrollando su propia recreación cultural, diferenciándose exteriormente de la sociedad dominante. Al tiempo que van reproduciendo su propia estética de la ciudad y se hacen visibles en ella.

\section{EL PROCESO DE VISIBILIZACIÓN}

La agrupación de los inmigrantes en los mismos barrios o barriadas, va transformando paulatinamente la fisonomía de las ciudades, introduciendo una diversidad cultural que las convierte en auténticos mosaicos étnicos, obligando a los ciudadanos a adaptarse a espacios heterogéneos.

Pero, si el porcentaje de la emigración extranjera, en concreto la magrebí en España, no es significativo en relación a la población residente total ¿qué es lo que los hace tan visibles? Son varios los factores que influyen en esta visibilidad de los inmigrantes: Por una parte, está el ya mencionado de su concentración residencial en determinadas áreas, así como los largos periodos que pasan en las calles. Por otra, su gran movilidad, tanto dentro de sus barrios como hacia el exterior en sus desplazamientos en busca o hacia su trabajo y, finalmente, los signos externos identitarios que los hacen manifiestos y reconocibles. 
Al residir en barrios marginales donde no abunda el trabajo, el inmigrante se ve obligado a realizar desplazamientos, más o menos largos, para acudir a su ocupación o para buscarla. A lo que se puede añadir el hecho de que muchos se dedican a la venta ambulante. No obstante, el no tener un empleo estable les obliga a pasar temporadas desempleados, lo que incrementa su estancia en las calles. Asimismo la situación de irregulares de muchos de ellos junto al desempleo, el alcoholismo y el ambiente marginal en el que viven les impulsan a ciertas actividades delictivas, como son el tráfico de droga o la prostitución ${ }^{5}$, que contribuyen a la mala fama de sus barrios. Esta mala fama condiciona a sus posibles empleadores a la hora de contratarlos. Es lo que se denomina "discriminación estadística". Ésta consiste en que, en vez de dar trabajo a unas personas en razón a su capacidad laboral, se hace utilizando otros elementos, como son la raza, la pertenencia a un determinado grupo étnico o el lugar en que se vive. Factores subjetivos y sujetos a muchos estereotipos, que influyen en el empresario a la hora de contratar o no a un inmigrante magrebi y que, a su vez, favorece la permanente segregación de este colectivo.

Por otra parte al inmigrante, en aras de la tolerancia, se le pide una cierta invisibilidad, una aculturación restringida de carácter instrumental. A cambio de trabajo no se les demanda una adhesión explícita a los valores vigentes en la sociedad receptora, pero si se les exige que silencien sus valores propios, especialmente aquellos que puedan crear conflicto con los autóctonos.

En el proceso de adaptación del inmigrante al nuevo medio social, es importante para él el mantenimiento de sus costumbres y valores, de un espacio conocido en el que poder compartir sus propios códigos culturales. Es en estos espacios en los que su presencia se hace manifiesta, y en los que su visibilización se presenta como una estrategia identitaria con objeto de ser reconocido en el espacio público, en el espacio urbano.

Son varios los elementos externos que contribuyen a la visibilización del magrebí en los espacios urbanos. Además de la ya mencionada movilidad fuera de sus barrios existe una acentuada movilidad dentro de los mismos. El inmigrante magrebí cambia con frecuencia de casa, y suele compartir techo con otros inmigrantes de su mismo país o región, hecho que se acentúa aún más entre las mujeres. Las mujeres marroquíes solteras o con la familia en el país de origen, aunque se dediquen al servicio doméstico suelen mantener un segundo domicilio para el dia libre. Este domicilio, que suelen compartir con otras chicas marroquíes, familiares o no, a la larga, se convierte en su principal lugar de relación social.

5 Cuando se habla de prostitución, generalmente se asocia a la prostitución femenina. No obstante la prostitución entre las mujeres marroquíes no es un hecho frecuente en núcleos urbanos en los que esta inmigración es antigua, como pueden ser Madrid o Barcelona, siendo relativamente más numerosa en áreas de migración femenina individual reciente, como Málaga o Almería. Un hecho que aparece como cada vez más habitual es la prostitución masculina, sobre todo entre los más jóvenes, asi puede observarse, por ejemplo, en la zona denominada El Malecón en la ciudad de Murcia, por la noche. 


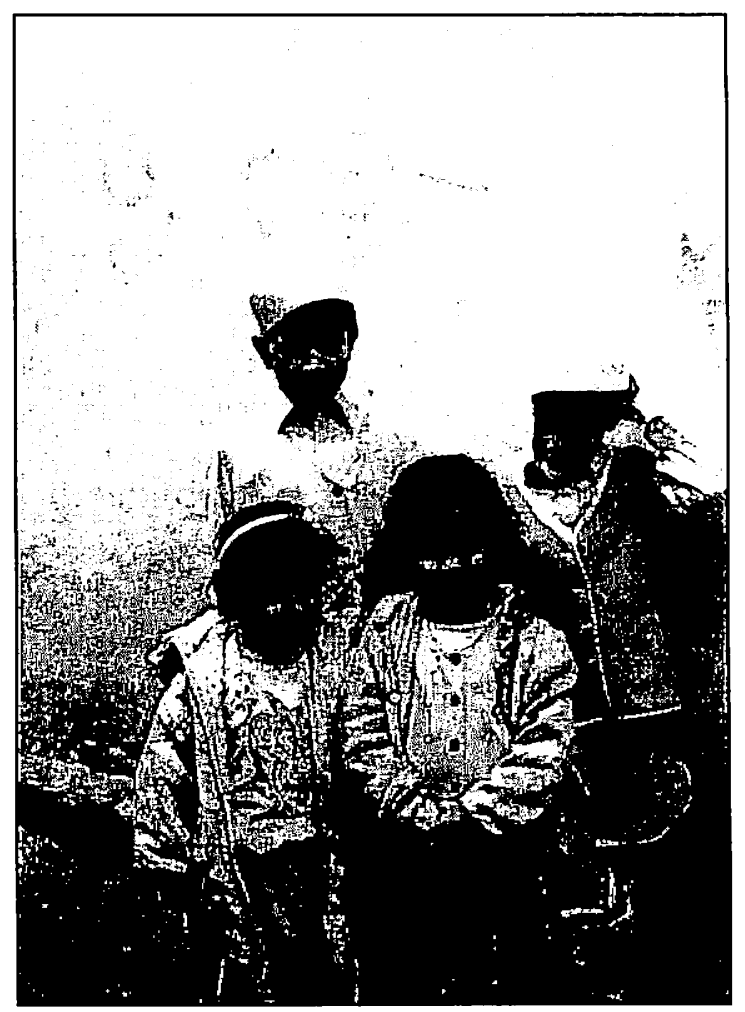

Niños magrebies vestidos de fiesta en el dia de la fiesta del cordero (Aid el Kebir). Aungue es más frecuente ver a los adultos usando la ropa tradicional, los niños también la usan en deter. minadas ocasiones, como son los acontecimientos festivos.

Otro factor es la vestimenta característico de estos grupos. Pese a que la mayoría de los hombres y gran parte de las mujeres visten a la manera occidental, procurando pasar desapercibidos entre la población mayoritaria, se observa un incremento reciente de aquellos que visten a la manera islámica, tanto por motivos religiosos como por ser una seña de identidad -si bien ambas cosas están intimamente relacionadas-. Esto se da especialmente entre las mujeres, que cubren sus cabellos con el hiyab o pañuelo y van vestidas con largas faldas y blusones que disimulan su silueta. Entre los hombres no es tanto una vestimenta característica, como una actitud y algunos elementos estéticos, como son las barbas cortas a la manera islámica, es decir, con una longitud máxima de cuatro dedos. Aunque es posible encontrar a varones marroquíes, especialmente aquéllos que se adscriben a ciertos grupos religiosos pietistas, como el tablig ${ }^{6}$, que sí van vestidos con yilabas blancas y, en algunos casos, turbante.

La aparición de diversos negocios, con sus letreros y signos característicos, contribuye a la visibilización del inmigrante en el espacio urbano. Estos pequeños negocios aportan ele-

6 El movimiento tablig (Sociedad para la Propagación del Islam) es la organización transnacional más grande que existe en la actualidad en el mundo. Su objetivo es recuperar y mantener el fundamento religioso de la comunidad musulmana por medio de al producción de una fuerte identidad islámica en aquellos lugares donde éstos son minoria y se hallan sometidos a fuertes procesos de aculturación por una sociedad y un poder no islámicos. 
mentos dinamizadores al barrio por varios motivos, como es la introducción de nuevos hábitos de consumo, al presentar nuevos productos como especias diversas, conos de azúcar, etc.; la implantación de nuevos servicios, como es el variar la hora de apertura y cierre de los pequeños establecimientos, al adecuarse al horario de las oraciones en la mezquita o a las jornadas laborales de los demás inmigrantes. Pero también pueden llegar a facilitar o entorpecen las relaciones con los demás grupos, de esta forma no es raro observar a los españoles que se autoexcluyen de comprar o entrar en dichos establecimientos.

Las tiendas magrebies son espacios de acción social. Lugares sonde se hacen circular noticias, lugares de negociación y venta, pero también lugares de interacción privilegiados, puntos de encuentro donde se charla, se toma un te verde, o simplemente, se sienta uno en las sillas puestas en la puerta, o se apoya en la pared, a mirar en silencio el desfile de transeúntes.

Los establecimientos más frecuentes son las carnicerías halal. En ellas, a demás de la carne sacrificada ritualmente según los preceptos islámicos, se vende una amplia gama de productos, tato de alimentación -sémola de cuscus, miel, conos de azúcar, especies y frutos secos...- como cintas magnetofónicas con la salmodia del Corán, explicaciones de sabios o música del Magreb; incienso, henna, kohl, relojes despertadres que llaman a la oración (reloj-adhan), hiyabs, etc.

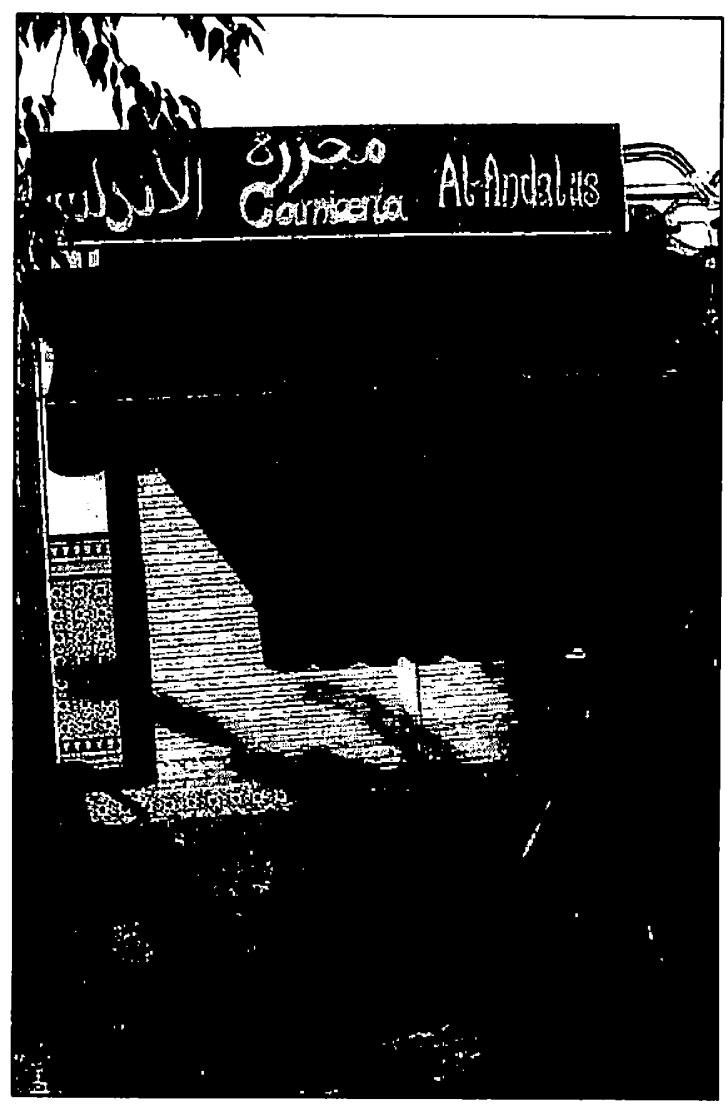

Los alimentos halal incluyen desde carne hasta productos enlatados, ya que la prohibición del consumo de cerdo llega al extremo de que exista una lista de emulgentes alimentarios prohibidos, por estar elaborados a partir del semen de cerdo. Entre estos emulgentes se encuentra el E-471 y el E-472, que so los más frecuentes en los productos envasados, como el pan de molde, y en los precocinados como las empanadillas. Los productos que se venden en una carnicería halal no contienen ninguno de estos emulgentes.

Carniceria halal en la ciudad de Sevilla. 
Otros locales regentados por magrebíes son las tiendas tipo "todo a 100 ", de marroquinería, los restaurantes étnicos, bares a los que van los inmigrantes, y donde raramente van las gentes del barrio o de la ciudad.

Los oratorios de barrio o "mezquitas", como prefieren llamarlas los inmigrantes, son también espacios que contribuyen a la visibilización del magrebi en el espacio urbano. La mezquita, al igual que las tienda, son lugares de reunión, espacios donde se desarrolla fundamentalmente la sociabilidad masculina. Su presencia está indicada por un letrero que, con frecuencia, está escrito con caracteres árabes, marcando así su diferencia con la sociedad que les rodea, al tiempo que contribuye a hacerlos patentes entre los demás habitantes del barrio.

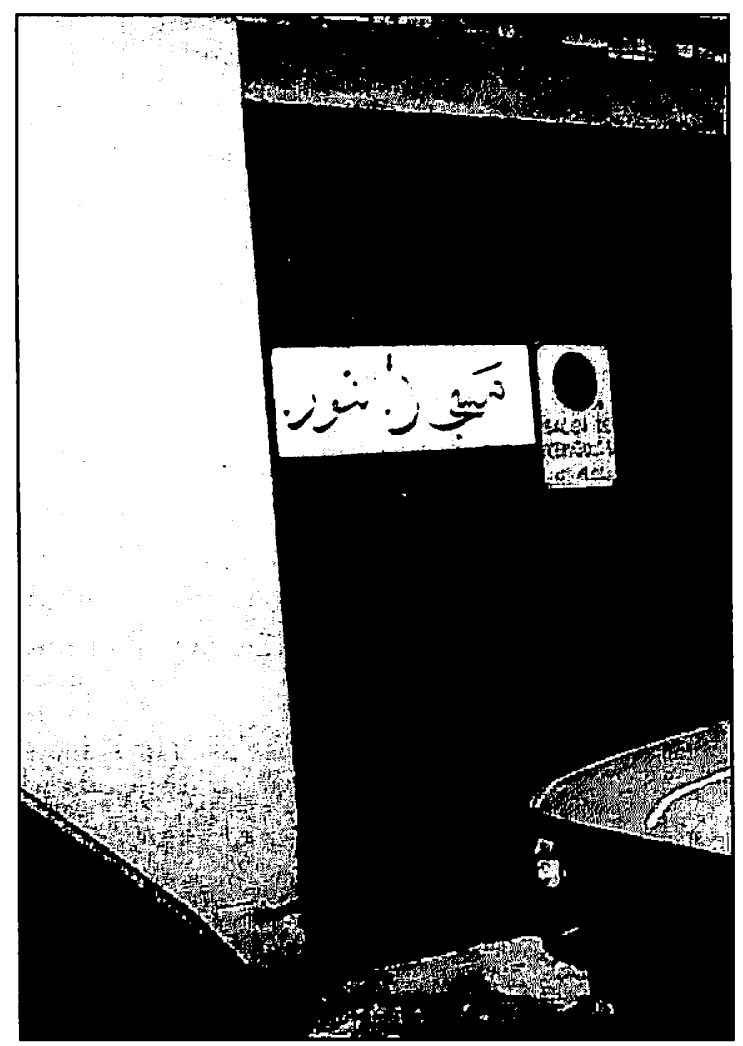

Oratorio de barrio-mezquita ubicado en un garaje que ha sido acondicionado para este uso.

La ubicación de una mezquita no requiere de un lugar especial, sino que en muchas ocasiones, son habitaciones en domicilios particulares o, más frecuentemente, garajes acondicionados para hacer la oración: un espacio más o menos amplio, con el suelo cubierto de alfombras; un lugar que indique la qibla (La Meca) y otro donde poder hacer las abluciones rituales imprescindibles para realizar la oración. Estas mezquitas son espacios multifuncionales que, además de ser centros de oración, funcionan como estructuras de asistencia social, en las que el inmigrante recibe apoyo y ayuda en sus necesidades individuales, tanto materiales como psicológicas. 
Cuando un hombre magrebi llega a una ciudad en la que no conoce a nadie, o cuando no encuentra los contactos que le indicaron en su lugar de origen, acude a la mezquita en busca de ayuda y cobijo. Es frecuente que en las mezquitas se acoja a otros musulmanes por un tiempo máximo de tres días, que es el establecido para la hospitalidad islámica. Este trajin de individuos, casi en su totalidad hombres, a lo largo del dia en las cercanías de los oratorios contribuye a su visibilización.

Asimismo es frecuente, en muchas ciudades, que estos oratorios de barrio o mezquitas estén abiertas prácticamente todo el día, ya sea acogiendo a los recién llegados, ya sea para realizar alguna de las cinco oraciones preceptivas diarias, las cuales están sujetas a un horario perfectamente establecido. Por lo que en los momentos anteriores y posteriores a estas oraciones (salat), son numerosos los magrebies que se acercan a estos oratorios.

"A la mezquita viene mucha gente. Casi todos para reza, pero hay otros que vienen buscando gente. Si está el salat, la oración, pues se esperan fuera, fumándose un cigarrillo. En la mezquita muchas veces hay gritos, discusiones, sobre todo cuando alguien quiere imponer su opinión, pero también cuando alguien se compromete a hacer algo y no lo hace, y todos le acusan de no hacerlo. A los marroquis nos gusta mucho chupar alfombra, tomar te y hablamos demasiado. Eso trae problemas." (Ali, 32 años, Marrakesh)

Pero no son sólo las oraciones, en la mezquitas se realizan otros rituales festivos como pueden ser la celebración de aqiqa (ritual de imposición del nombre al recién nacido), y los matrimonios, además de los asociados al ayuno del Ramadán, entre otros.

Otros puntos de reunión de los magrebles en las calles, y que contribuyen a hacerlos más presentes en los barrios, son las cabinas telefónicas. Ya que la mayoría carece de línea telefónica en sus casas, es frecuente verlos por las noches, cuando las tarifas son más baratas, haciendo cola ante una cabina, charlando o discutiendo entre ellos.

De este modo el inmigrante magrebi, en tanto que actor social, se desplaza por el interior de un espacio compartido, se hace visible en el interior de dicho espacio. El barrio, la ciudad, es continuamente construida, se negocia y se interpreta de forma múltiple.

Por medio de la reproducción en la ciudad de determinados referentes identitarios, en este caso elementos materiales en los barrios en los que viven o en los que se concentran en mayor número, el inmigrante destaca los límites de su especificidad. Límites que, además de en los discursos, son formulados en las prácticas cotidianas que, a modo de marcadores de identidad, recuerdan hacia el interior y hacia el exterior del grupo la sociedad que les separa de la sociedad receptora.

Un proceso con propósitos manifiestos, como es el de responder a unas determinadas demandas y necesidades de tipo colectivo. Con finalidades implícitas, como es la de configurar una conciencia identitaria colectiva. $Y$ cuyo objetivo principal es conseguir mantener y reproducir el vínculo comunitario, como una forma de evitar la disgregación social y la aculturación del grupo.

Esta visibilización del colectivo inmigrante en la ciudad entra en conflicto con la exigencia de la sociedad receptora de la aculturación restringida. Conflicto del que resultan, en 
algunos casos, brotes de violencia pero que, en la mayoria de ellos se resuelve con una supuesta tolerancia. Se trata de una condescendencia que esconde un claro desinterés hacia los demás, puesto que en el fondo persiste una estrategia colectiva que permite superar la desconfianza, la inseguridad o el malestar que generan algunos grupos étnicos en la sociedad mayoritaria. Es decir un talante de total indiferencia hacia la novedad y la diversidad, una actitud que es el resultado de presión social que rodea al individuo, neutralizando sus sentimientos y llevándole a la no implicación en la vida de la ciudad.

\section{CONCLUSIONES}

La ciudad es, en definitiva, un espacio social para la reciprocidad y la interacción, que se conforma atendiendo a todas las variables culturales posibles de una sociedad determinada. En ella se definen tanto los aciertos como los problemas de cada momento histórico.

Uno de los fenómenos que caracteriza la época presente es el incremento y el carácter de los flujos migratorios. Migraciones que tienen a las ciudades como lugar de destino, y que favorecen el contacto entre dos más grupos étnicos distintos. Grupos entre los que se establecen diversas relaciones de poder y que desarrollan variadas estrategias de adaptación al medio.

En la ciudad coexisten, por tanto, grupos étnicos dispares. Por una parte una sociedad receptora, con su propia cultura y señas de identidad. $Y$ por otra distintos grupos migrantes que se constituyen en minoría en tanto que se reconocen y son reconocidos como grupos culturalmente distintos.

Al inmigrante, al magrebí en este caso, la sociedad mayoritaria le exige una cierta invisibilidad en aras del la estabilidad u orden social. Esta invisibilidad, similar a la que se le pedía en las ciudades norteafricanas durante el periodo colonial, es la que empuja a estos grupos minoritarios hacia las zonas de exclusión de las ciudades.

No obstante estos grupos inmigrantes, haciendo uso de estas estrategias de adaptación, han extrapolado a la sociedad receptora sus propias señas de identidad, reclamando su lugar en el espacio público y haciéndose visibles en la ciudad.

En definitiva, y a pesar de que se pueda hablar de segregación y exclusión social de los grupos minoritarios, esto no implica que se encuentren aislados sino que se hallan en un contacto continuado e intimo con la sociedad mayoritaria, constituyendo una parte integral de la sociedad urbana.

\section{BIBLIOGRAFÍA}

BENKIRANE, R.: Bidonville et recasement, modes de vie à karyan ben M'sik (Casablanca). Archipress, Géneve, 1996.

BETTIN, G.: Los sociólogos de la ciudad. Gustavo Gill. Barcelona, 1982

MARTÍNEZ VEIGA, U.: "Pobreza, exclusión social y segregación espacial", en Areas, Murcia, 1999. $\mathrm{N}^{\mathrm{v}} 19, \mathrm{pp} .35-50$

LAURENS, H. (ed.): Histoire de l"urbanisme. Laurens. Paris, 1952 
MONNET, N.: "Prácticas urbanas y sociales de los grupos que conviven en el casc antic de Barcelona". Comunicación presentada en el II Congreso sobre la Inmigración en España. Madrid, 2000

PROVANSAL, D.: “De qué migración hablamos? Desde los conceptos a las prácticas sociales". En Inmigrantes entre nosotros (Checa y Soriano, edts.) Icaria, Barcelona, 1999, pp. 17-32 